\title{
Development and Approbation of the Technique of the Assessment of Expediency and Budgetary Productivity of Introduction of the Tax Privilege
}

Bezrukova T.L.

\author{
Voronezh State Academy of Forestry and Technologies, Voronezh, Russia
}

Sibiryatkina I.V.

Voronezh State Academy of Forestry and Technologies, Voronezh, Russia

Ryzhkov A.0.

Voronezh State Academy of Forestry and Technologies, Voronezh, Russia

Bryantseva L.V.

Voronezh State Agricultural University, Voronezh, Russia

\section{Doi:10.5901/mjss.2015.v6n3s6p67}

\section{Abstract}

Practical need of the national economy of the Russian Federation in research on the use of tax incentives to stimulate innovative activity defined goals, objectives, subject and object of the present study. The aim is to develop a methodology for assessing the impact of the tax incentives from the point of view of the state. In accordance with this purpose the following tasks are formulated and substantiated in the work: creating guidelines to improve tax incentives to stimulate innovative activity in the Russian Federation; development of methodology for assessing the fiscal impact of tax incentives in Russia using the methods of correlation and regression analysis. The developed technique is applied taking into account already introduced incentives and it is able to be applied for adjustment of the tax policy of the state. Under the definition of "fiscal effectiveness" of incentives we understand correspondence of 1) additional $R \& D$ costs in the economy as a whole due to the introduction of benefit itself (" result ") and 2) in the amount of shortfall in budget revenues from the introduction of the tax benefits that could have been spent on $R \& D$ directly (e.g., by government order), and this increases the level of $R$ \& $D$ expenditures for total economy ("cost"). This definition is based on the fact that the size of $R \& D$ expenditures is a sign of innovativeness of the economy. Scientific novelty consists in the fact that the technique of assessing the budgetary effectiveness of application of the tax. The technique lies in correlation and regression analysis of statistical data, identifying the size of the additional $R \& D$ expenditures caused by introduction of particular incentives and comparing values of these costs with the size of the budget shortfall in income due to the introduction of incentives. The method was tested on the example of the income tax. Inappropriate use of regional benefits for income tax for the companies - manufacturers of high-tech products is proved.

Keywords: analysis, testing, innovation, incentives, research and development.

\section{Introduction}

The need for regulation of innovation activity by the state is widely recognized at least due to the fact that research and development can be not only a private nature, can not only lead to a private goal, set by researchers and entrepreneurs, but also contribute to technological breakthrough in some sectors of the economy.

There are some arguments against the use of tax incentives to stimulate innovation. In particular, business entities can carry out innovative projects regardless of whether or not benefits are provided. The fact of giving incentives will not affect in this case the activity of a particular company in innovation, but it will reduce tax loss (and increase them for the state).

Innovation - oriented tax incentives differ in kinds, countries and have different effects on different companies in different conditions. Constant changes in tax policy, both foreign countries and the Russian Federation, give, on the one hand, extensive material for the study of effectiveness, efficiency, management innovation through tax incentives, primarily by means of statistical methods, correlation and regression analysis, on the other hand, make it difficult to 
analyze because of the large number of other "noise" factors.

Theoretical and methodological basis of research included the works of Russian and foreign authors on tax incentives as a tool to stimulate innovative activity, the need to introduce tax incentives, both in terms of the state, and from the point of view of the individual subjects of the national economy. Works by K. Swenson, F. Meyer-Kramer, P. Berger, E. Mansfield, M. Nadiri are devoted to assessing the effectiveness of tax incentives. The desirability and feasibility of using the value of $R \& D$ expenditures in the economy as a whole as an indicator of innovativeness in terms of effectiveness of tax incentives is noted in the works of R. Hall, P. White and E. Mansfield. The complexity of the need to use tax incentives as a tool to stimulate innovation and active organizations is touched in the works by AG Granberg, SV Valdaytsev, OP Karavaeva, VI Gureev. Works by VJ Kozhinov, AG Karu, DY Melnik, DI Kokurin, VG Panskov, OV Motovilov, TF Yutkina, OV Savvina, and other are devoted to the main problem of tax systems, assessing and features aimed at stimulating innovation activity.

Subject area is the methodological problems of feasibility of stimulating innovation activity of the national economy through tax incentives.

To implement these goals, the method of comparative analysis, the method of grouping, system analysis, functional and structural analysis, economic and statistical studies and mathematical methods to assess the effectiveness of various tax preferences are used. The use of qualitative methods is necessary due to the fact that quantitative methods in a specific way are limited in their application.

The result of the study is developed method of assessment of appropriateness and fiscal effectiveness of tax incentives.

\section{Consideration of the Leading Valuation Techniques of Budget Effectiveness of Tax Incentives}

\subsection{Basic approaches to evaluating the effectiveness of fiscal policy}

Currently, there are two main approaches to the evaluation of the effectiveness of any tax policy.

The essence of the first approach is related to the clarification of whether the level of supply of goods (services) after application of stimulus measures so that the social return is equal to public costs. In this situation comparison of two values is required:

Limit (marginal) returns at the level of society as a whole from each additional ruble spent on research and development;

The opportunity cost of using the shortfall in tax revenues (for example, the costs of direct funding of $R \& D$ through public procurement).

This method is too complicated for its practical implementation. It is almost impossible to quantify the first indicator of the large uncertainty. At least, the author could not found in works of both domestic and foreign authors attempts to use this method, or similar notices.

Most researchers sometimes simplify this method and to address the effectiveness of application of benefits formulate two consecutive questions (Mansfield E., Switzer L.1985):

- what impact (in percentage terms) had one or another tax benefit to change the level of expenditures in research and development for inflation?;

- how much effectively are incentives used in terms of comparing the size of the shortfall in tax revenues that could be spent on direct support to the innovation sector, and the additional costs of research and development due to privilege?

Of course, the increase in spending on research and development, as though it may be precisely measured, can not fully reflect the effect of the introduction of benefits. However, taking into account a number of assumptions, it can be argued that the use of the level and dynamics of $R \& D$ expenditures is highly accurate way to measure effectiveness of application of benefits. In economic studies on the subject, some understanding of the possible approaches to quantification of the effect of the introduction of particular benefits are has developed. The proposed methods can be divided into:

- empirical (case studies);

- Analytical - correlation and regression analysis of the data for statistical or tax authorities.

Let us examine them in more details. When using empirical methods the following procedures are performed:

- focus group of business executives who could potentially take advantage of the privilege is selected;

- each respondent is presented a list of questions about how the introduction of particular tax benefits has developed affected (could affect) the level of R \& D costs; 
- $\quad$ the responses are statistically processed.

Corporate executives can actually take into account various other factors that are often not taken into account when using analytical methods.

On the other hand, these estimates may overstate the impact of benefits on the company's expenses for research and development, as companies usually encourage the introduction of incentives. In addition, it is difficult and time consuming to apply this method for a representative sample of respondents. In other words, risk of significant distortion of the real situation of the human factor is big enough.

However, this method is actively used, including public authorities (such as the Ministry of Finance of Canada in 2007 to assess the impact of tax deductions (tax credits) for income tax). Its use to assess the impact of planned changes would seem appropriate as other methods, as it will be shown below, not always resemble for these purposes. Representatives of 345 companies responded to the questionnaire consisting of 21 questions. The study results are graphically designed in the charts and histograms, which allows giving answers to the Ministry of Finance of Canada on the questions. For example, the study identifies the main problems of using incentives used from the point of view of companies - mostly - on additional administrative paperwork. The majority of respondents (86\%) answered that increased incentives used for research and development have a positive impact on the level of costs.

\subsection{Foreign experience of implementation of tax deductions}

In studies on effectiveness introduction of tax deductions in Canada in the 1980s, Mansfield and Switzer analyze effectiveness of benefits for research and development as follows: (Response to the Department of Finance, Canada. 2007):

- make up sample of respondents (managers of large firms, carrying out cost of research and development);

- justify the representativeness of the sample (55 firms);

- carry out analysis;

- statistically characterize the results of the analysis, pointing out, for example, the confidence interval for the value of the cost of research and development, initiated by benefits;

- $\quad$ explain obtained results using mathematical apparatus and economic essence of studied phenomena.

Edwin Mansfield rightly notes that the survey of the views of representatives of companies can be quite optimistic. The resulting estimates may overstate the impact of benefits on the company's expenses for research and development, as companies often encourage the introduction of incentives. Indeed, given the fact that the representative of the management of interrogated company represents ifinal report recipients (most of all - government bodies), his/her best interest is to overstate the importance of the benefits for the company. In a situation where he/she does not know whether the company will enjoy the benefits or not, more likely positive response will be get only because of the real interests of the interviewee to maintain preferential tax treatment or get new benefits.

The advantage of case-method can be called that the manager actually takes into account other factors, and provides the most accurate answer to the question "How will the benefits affect/ affected to the costs of research and development." Most likely, he/she will eliminate those situations where a company and so would make an additional investment in science without fringe benefits.

The disadvantage, as already noted, is subjectiveness of responses and the human factor. Both an advantage and disadvantage is a small number of firms that are used for the analysis. Incorrectly selected sample may not be representative and nullify all the results of research.

The author believes that such a review can be carried out in relation to the Russian Federation, however, is not placed among the tasks of this work.

More accurate results can be obtained using analytical methods based on statistical data processing. Among them we distinguish the following, the most common.

\subsection{Demand equation for research and development with a binary variable for tax credit}

This method is based on the classical model of multiple regressions. It is assumed that the level of expenditure on research and development (both at the i-th firm, and at the macro level) at time $t$ is a function of a number of variables. These variables can be a variety of factors - the level of expenditure on research and development in the previous period, the expected cash flows, the expected level of demand for manufactured products, inflation, etc. The selection of the factors affecting the level of $R \& D$ expenditure according to the researcher is one of the important stages of the calculation of performance of benefits of the proposed method. Of all the factors parameter distinguished which is equal 
to "1" in the case of the availability of tax incentives for research and development and "0" in the absence of such benefits. In other words, the equation is constructed, which in its most general form is as follows: (Swenson, C.W. 1992):

$$
\mathrm{Y}_{\text {it }}=\alpha_{0}+\alpha_{1} * \mathrm{X}_{1 \mathrm{it}}+\alpha_{2} * \mathrm{X}_{2 \mathrm{it}}+\alpha_{3} * \mathrm{X}_{3 \mathrm{it}}+\alpha_{4} * \mathrm{X}_{4 \mathrm{it}}+\mathrm{U}_{\mathrm{it}}
$$

Where $Y_{i t}-$ level of expenditure for research and development in the period of time $t$;

$\alpha_{0}$ - constant, reflecting non-functional link between the variable and the resulting factors;

$\alpha_{1}$ - boost factor expressing additional costs for research and development, caused by the introduction of appropriate incentives;

$\mathrm{X}_{1 \mathrm{it}}$ - fictitious (or binary) variable equal to " 1 " if the tax benefit is available, and is equal to "0" if not. This variable is introduced in order to fix the boost factor, the weight of factor of "availability of tax incentives" in the growth of spending on research and development;

$\mathrm{X}_{2 \mathrm{it}},-$ level of expenses for research and development in the period $\mathrm{t}-1$;

$\mathrm{X}_{3 \mathrm{it}}$, - expected demand for products in the period $\mathrm{t}$;

$\mathrm{X}_{4 \mathrm{it}}-$ probable balance of cash flows in the period $\mathrm{t}$;

$\left(\mathrm{X}_{2 \mathrm{it}}, \mathrm{X}_{3 \mathrm{it}}, \mathrm{X}_{4 \mathrm{it}}\right.$ - various factors that influence the cost of research and development in period $\mathrm{t}$ for each company or for the economy as a whole. Various studies of the number and types of variables may differ, often their numbers in the used models are much more);

$\alpha_{2}, \alpha_{3}, \alpha_{4}$ - coefficients of relevant variables $\mathrm{X}_{2 \mathrm{it}}, \mathrm{X}_{3 \mathrm{it}}, \mathrm{X}_{4 \mathrm{it}}$, determined as a result of statistical processing of numerical data.

$\mathrm{U}_{\text {it }}-$ stochastic (probabilistic) error. method.

The above equation is constructed in the most general form, in order to give an idea about the basics of this

Equation (1) is based on the assumption that there is a relationship between the resulting $\mathrm{Y}$ and $\mathrm{X}$ variables.

Linear relationship of factors and the resulting variable is often far from the real picture - observations show that nonlinear relationship gives more correct results. However, through the use of logarithms it is easy to lead function to linear, standard form.

The essence of the implementation of this model for assessing the effectiveness will be considered by the following stages.

1) The factors, according to the researcher, affecting the level of research and development are determined.

2) A series of observations is produced, usually on the basis of statistical data in two possible ways:

A) Microeconomic level ( $i$ - firm). Research is conducted at the level of firms within the same time period (e.g., year).

Then $\mathrm{Y}_{\text {it }}$ it will cost at the firm level. Through surveys, or by using the access to the statistical databases on corporate reporting, a set of collections of values of the function and the factors is get.

B) Macroeconomic level (in this case $Y_{i t}=Y_{t} ; X_{n i t}=X_{n t}$ ). Using data from the macro-economic statistical surveys or other available data, a set of collections of values of the function and the factors is get throughout the economy as a whole (or a particular industry) for the various periods (e.g., years).

3) Further, using the theoretical apparatus of mathematical statistics (correlation and regression analysis) and data processing software, the coefficients are found. Thus, we can estimate how much the average percent growth in spending on research and development was caused by the introduction of specific incentives.

Need for valuation of variables should be noted when moving from the absolute values of the data (and the resultant factors) to the standardized deviations. For example:

$$
\begin{aligned}
R_{i t}^{*} & =\frac{\mathrm{R}_{\mathrm{it}}-\overline{\mathrm{R}}}{\sigma_{\mathrm{R}_{\mathrm{it}}}} \\
X_{i t}^{*} & =\frac{\mathrm{X}_{\mathrm{it}}-\overline{\mathrm{X}}}{\sigma_{\mathrm{X}_{\mathrm{it}}}}
\end{aligned}
$$

Where: $\sigma$ - mean-square deviation;

$\bar{R}$ - Arithmetic mean $\mathrm{R}$.

Rationing variables solves the problem of comparability of different variables (e.g. interest rates on loans and the level of expenditures in research and development).

4) Growth of expenditures on research and development, caused by the introduction of benefits and losses of the state budget from the introduction of incentives is compared. If the first is higher than the second, benefit is effective. If the loss is greater than the corresponding increase in costs, direct funding for $R \& D$ is more efficient (for example, through the state order, assuming the absence of corruption and other external factors).

5) Development of measures to improve benefits (optional). 
The advantage of research at the level of individual firms is primarily produced in more accurate conclusions. If the data set lies in aggregates by periods (e.g., by years), the results are likely to be less accurate, but on the other hand, the study will be considerably less time consuming. The key point in the construction of this model is the selection of the most relevant variables depending on the particular region, time period and general characteristics of the innovation economy.

\subsection{Estimated elasticity of demand on research and development}

This method is similar to the previous one. It is based on the construction of multiple linear regression models of the dynamics of the cost of research and development for a number of independent factors, which include key indicator - an index of changes in prices of basic resources used for R \& D: the wages of scientific and technical personnel, equipment, running costs (materials), other.

With the help of the mathematical apparatus it is possible to estimate the effect of changes in prices for these resources on the level of costs of research and development. Factor reflecting this relationship will be the coefficient of elasticity of demand for research and development for the price. Evaluation of this factor in various studies regarding the various economies differs greatly. However, it is possible to draw conclusions:

- $\quad$ According to studies carried out in the 80s, the whole coefficient is rarely more than "1" (coefficient equal to "1" means that the reduction in the cost of basic resources used for research and development, by $1 \%$ leads to an increase in costs). It is worth noting that, in assessing the effect only the first three years after the introduction of privileges were taken into account;

- According to more recent studies (the 90 s and later) the long-term elasticity (2-5 years) is in 2-3 times higher than the short-term (1-2 years) one and often it is higher than "1". In other words, it is the effect of reducing;

- The cost of research and development is fully manifested within a few years after such decrease. This observation led at some point to an overestimation of the effect of tax incentives for increased spending on research and development.

As it is noted in the "Effectiveness of accelerating scientific and technological progress," after 2-3 years after the introduction in the early 80-ies in the USA tax incentives to encourage investments in science, spending on research and development in this country increased by only $1-2 \%$. "However, most of the tax savings for businesses and associated losses for the state budget (60-70\%) firm directed not to stimulate the targets (i.e., not science), but the expansion of production, its diversification, etc." (Mansfield E., Switzer L. 1985).

We can assume that such a conclusion is based on the analysis of the impact of short-term benefits. In the first year or two after the introduction of benefits possibly not all companies in which the privilege is aimed, will take advantage of it. Making decisions about new projects, investments may take a longer period. In addition, the so-called "chain reaction» has specific value - some companies are important to see the successful use of incentives, to hear from partners, to ensure that the mechanisms of tax policy work in practice without creating additional risks.

Therefore, in the formation of the data samples for analysis, at least a few years after the introduction of incentives should be included in the study area, as impairment of resources used for research and development is fully manifested within a few years after such decrease.

Next, how much benefit can reduce the cost of research and development is estimated. It's easy enough to make tax deductions for income tax. In Russia such privilege has been introduced since 2009, which has become abroad one of the most popular ways of tax incentives for innovation sector, in which the taxpayer's expenses on $R \& D$ for tax purposes can be considered with coefficient of 1.5 .

Let's assume that a certain company has a positive tax base for income tax. In normal tax regime one ruble spent on $R$ \& $D$, can reduce income tax by 20 kopecks. This means that the total costs of the company from spending each additional ruble for $\mathrm{R} \& \mathrm{D}$ with the tax savings will amount to 80 kopecks. In the case of the presence of the tax deduction with coefficient 1.5, each additional ruble spent for $R \& D$, can reduce income taxes by 30 kopecks (20\% * 1.5 rub.). As a result, the overall cost of each additional ruble pending on for $R \& D$ would be only 70 kopecks.

In other words, assuming that a certain company carries out research and development solely on a list approved by the Government of the Russian Federation, this benefit will reduce the cost of the research and development about $12.5 \%\left(\frac{(0.80-0.70)}{0.80}\right)$. If the elasticity of demand for research and development is, for example, 0.5 , then the effect of the introduction of incentives must be accompanied by about $6 \%$ increase in spending on research and development.

One of the most important advantages of this method is that it can be used to analyze the effectiveness of benefits still intended for administration. The previous method may be only used for analysis of the performance of benefits which are already introduced, as it implies the existence of the data sets to the same extent as before the introduction of 
incentives and after it.

If benefits do not assess how much it generally lowers the cost of research and development, the use of this method is impracticable. In practice, the choice of a particular method for assessing the effectiveness of benefits often depends primarily on the ability to obtain statistical data on both companies individually to form a representative sample, and in general on industry or country at different times to form the required set of data sets.

Thus, it can be concluded that:

- mainly impact assessment is based on the methods of correlation and regression analysis, statistical data, and suggests volumetric calculation;

- there is no single approach to impact assessment, valuation models are mainly subjective, dependent on the author's approach, in this connection, for the same countries and time periods, there are different conclusions;

- to assess the performance before the introduction of benefits is rather difficult;

- most researchers came to the conclusion that the impact assessment, made one or two years after the introduction of benefits greatly underestimates the effect (increase in spending on research and development of the private sector, caused by the introduction of benefits) due to the sluggishness of price adjustments of the companies;

- to make decisions about the beginning of new projects, companies often want to see the application of benefits in practice, judicial practice, the experience of competitors, etc.;

- calculation of the tax deduction for incremental basis (as a percentage of growth in spending on research and development in the current year compared to the previous) is weakly stimulates business to additional costs, leads to the manipulation of costs ( taking into account the benefits factors in the planning of the dynamics of the cost of research and development). As it will be seen from further analysis, almost all countries that use incremental basis for calculating the deduction, modified it significantly (the mechanism for calculating is nontrivial);

- in general, studies on the impact of tax incentives used in different countries now show that the benefits in the form of an additional tax deduction (introduced in the Russian Federation since 2009) are generally effective and can lead to an increase in expenditure on research and development to 2 currency units (CU) for $1 \mathrm{CU}$ of budget losses from the introduction of incentives. In other words, benefit in this case is 2 times more effective than direct support for innovation and research funding by the State (General Accounting Office. 1996).

\section{Development and Implementation of Methods for Assessing the Effectiveness of Tax Incentives for Companies of Innovative Sector of the Economy}

Currently, the Law of St. Petersburg "On tax benefits" provides benefits for income tax in the form of lower rates of regional components in such a way that the total tax rate is reduced from $20 \%$ to $15.5 \%$ for manufacturers of certain types of high-tech products, which carried out investments in fixed assets in the amount of not less than $50 \mathrm{mln}$. rubles. This privilege aims to reduce the cost of innovation projects, it increases their attractiveness to investors, and therefore we can assume that it is able to stimulate the growth of innovative activity.

The fact that the benefit reduces income tax rate for the company as a whole, does not assess the after-tax cost reduction of ongoing research and development. This is due to the fact that the value of savings from the use of company benefits will depend on a number of factors unrelated to the magnitude of the costs of research and development (for example, added value created at the level of the company). And if it is impossible to estimate the after-tax cost reduction of the research and development (in relative terms), then to evaluate the effectiveness of incentives through the elasticity of demand for research and development is not possible. Therefore, we consider the possibility of using the first of the above two analytical methods - through the equation of demand for research and development with a binary variable for the tax credit.

First you need to determine what data will be used - at the macroeconomic level or at the level of economic agents (micro-level). As it is noted above, the first method is on the one hand is simpler from the point of view of availability and simplicity of required calculation data, on the other hand, it gives less accurate results, as the second one (there is no assurance that all companies equally respond to introduction of tax benefit through increased spending on research and development).

For the formation of an array of data on the level of expenditure on research and development and factor values that affect the level of such costs at the level of individual companies, access at least to their financial statements is needed. In Russia, at the moment there are some difficulties in obtaining access to such data sets. Data of state statistical observations suggest complete confidentiality of data on individual economic entities, in addition, the author 
managed to find databases containing information about the company's financial statements, but such information is "tax secret" and its dissemination is classified as a criminal offense, so author does not consider the provision of such information will be safe enough. The annual reports of public companies, data on expenditure on research and development are often absent.

For comparison, in the European Union, the United States, there are databases with paid access, containing information (including financial) of the non-public companies. Data for the study at the macro level can be obtained from officially published statistical bulletins containing information both for the country as a whole and for regions, and for research and development.

It seems reasonable (at least as a starting point) to resort to the analysis at the macro level because of data availability, at least in the state statistical observation of the Russian Federation.

\subsection{Algorithm of efficiency evaluation}

The author proposes the following algorithm of efficiency evaluation.

1. To determine what data you need to collect for analysis, it is necessary to construct factor model, that is, to determine the factors that affect the level of expenditure on research and development in the whole region. According to the author, it is advisable to include the following factors into the number of factors in the model given in equation (2), so that a special case of the model is as follows:

$Y_{\text {it }}=\alpha_{0}+\alpha_{1} * X_{1 i t}+\alpha_{2} * X_{2 i t}+\alpha_{3} * X_{3 i t}+\alpha_{4} * X_{4 i t}+\alpha_{5} * X_{5 i t}+\alpha_{6} * X_{6 i t}+U_{i t}$

Where $Y_{i t}-$ level of expenditures for research and development in the period of time $t$;

$\alpha_{0}$ - constant, reflecting the non-functional link between the resulting variable and factors;

$\alpha_{1}$ - boost factor expressing additional costs for research and development, caused by the introduction of appropriate incentives;

$\alpha_{2}, \alpha_{3}, \alpha_{4}, \alpha_{5}, \alpha_{6}$ - boost factors reflecting the influence of factors on the resulting function;

$\mathrm{X}_{1 \mathrm{it}}-$ subsidies, grants received by companies of St. Petersburg on research and development, in the year $\mathrm{t}$. Such forms of state support can encourage projects with high risks and, therefore, additional costs for research and development;

$\mathrm{X}_{2 \mathrm{it}},-$ level of expenditures for research and development in the whole St. Petersburg for the year $\mathrm{t}-1$. This factor is the base or, in other words, starting point of the level of expenditures for each subsequent period;

$\mathrm{X}_{3 \mathrm{it}}$, - the average cost of loans for small and medium-sized businesses in year t, offered by banks in the region. Relatively long payback periods of $R$ \& $D$ expenditures make the cost of debt financing a key factor in making decisions about the implementation of these projects;

$\mathrm{X}_{4 \mathrm{it}}$-volume of direct budgetary financing of public research organizations in the year t;

$\mathrm{X}_{5 \mathrm{it}}$ - dummy (or binary) variable equal to "1" if the tax privilege is available (since 2008), and "0" if not (until 2008). This variable is introduced in order to fix the boost factor, the weight of the factor of "availability of tax benefits" in the growth of spending on research and development;

$\mathrm{X}_{6 \mathrm{it}}$ - the level of gross domestic product of St. Petersburg in year t. Development of the regional economy as a whole for a number of industries stimulates demand including $\mathrm{R} \& \mathrm{D}$. Along with the change in volume of regional product and the demand for factors of production changes accordingly, to which a certain degree of conditionality can be attributed, and R \& D;

$\mathrm{t}$ - the calendar year for which data are taken.

2. Finding the regression coefficients through the use of statistical tools for this equation (namely, $a_{1}$ ) will determine how the introduction of this benefit influenced on the change in the level of research and development.

3. Comparison of the "contribution" of incentives with a corresponding loss of tax revenue will assess how effective it is, will answer the question, is not it more effective if there are direct subsidies to research and development in amount equal to the size of the loss in tax revenue? The size of the loss of tax revenues can be calculated directly, using data from the tax authorities about files of tax return for the relevant period (by multiplying the tax base of each company, said about the benefits to 0.055 , that is, the difference in tax rates). This is possible due to the presence of a specific space for a reduced tax rate in the tax declaration for profit of organizations.

Virtually all of these variables are the subject of state statistical observation in the field of research and development. The main source of information for statistical agencies is the form of "2-science", which is mandatory for all 
organizations of performing $\mathrm{R} \& \mathrm{D}$.

Thus, factor model assessing the impact of tax incentives is formed under the law of St. Petersburg "On tax benefits" for companies innovative sector, list of statistical data and tax authorities is formed required to assess the impact of incentives in terms of quantity.

\subsection{Factors of effectiveness of tax incentives}

To evaluate the effectiveness of incentives author considers it appropriate to include the following factors in the model:

$\mathrm{X}_{1 \text { it }}$ - subsidies, grants received by the companies of the Russian Federation to carry out research and development in the year t. Such forms of state support can encourage projects with high risks and, therefore, additional costs for research and development;

$\mathrm{X}_{2 \mathrm{it}},-$ level of expenditures for research and development in the whole of the Russian Federation for the year $\mathrm{t}-1$. This factor is the base or, in other words, starting point of the level of expenditures for each subsequent period;

$\mathrm{X}_{3 \mathrm{it}}$, - the average cost of loans for small and medium-sized businesses in year $\mathrm{t}$, offered by the banks of the Russian Federation. Relatively long payback periods of $R \& D$ expenditures make the cost of debt financing a key factor in making decisions about the implementation of these projects;

$\mathrm{X}_{4 \mathrm{it}}$ - average salary of programmers;

$\mathrm{X}_{5 \mathrm{it}}$ - dummy (or binary) variable equal to "1" if the tax privilege is available (since 2008), and "0" if not (until 2008). This variable is introduced in order to fix the boost factor, the weight of the factor of "availability of tax incentives" in the growth of spending on research and development;

$\mathrm{X}_{5 \mathrm{it}}$ - the level of gross domestic product in the year t. The development of the Russian economy as a whole in the range of industries stimulates demand including $R \& D$. Along with the change in volume of regional product and the demand for factors of production accordingly changes, to which a certain degree of conditionality $R \& D$ can be attributed;

$\mathrm{t}$ - the calendar year for which data are taken.

Let us consider how statistical surveys are organized with regard to the subjects of innovation on the example of Table 1.

Table 1. Forms of state statistical observations in relation to the innovation sector of economy

\begin{tabular}{|c|c|c|c|}
\hline № form№ & Title & Necessarily provided & Basic data \\
\hline 1 4-innovation & $\begin{array}{l}\text { Information about the } \\
\text { innovative activities of the } \\
\text { organization }\end{array}$ & $\begin{array}{l}\text { Legal entities and their subdivisions (except } \\
\text { small businesses) (according to the list } \\
\text { approved by the territorial body of the Federal } \\
\text { State Statistics Service). }\end{array}$ & $\begin{array}{l}\text { Volume and structure of innovative products, the cost of } \\
\text { innovative products, barriers to innovation, patenting }\end{array}$ \\
\hline 2 1-technology & $\begin{array}{l}\text { Information about creating } \\
\text { and using advanced } \\
\text { manufacturing technologies }\end{array}$ & $\begin{array}{l}\text { Legal entities and their subdivisions (except } \\
\text { small businesses), creating and using } \\
\text { advanced production technology (on the list } \\
\text { approved by the territorial body of Federal } \\
\text { State Statistics Service). }\end{array}$ & $\begin{array}{l}\text { Types of introduced advanced production technologies, } \\
\text { their patent purity }\end{array}$ \\
\hline 3 2-MP Innovation & $\begin{array}{l}\text { Information on the } \\
\text { technological innovation of } \\
\text { small enterprise (organization) }\end{array}$ & $\begin{array}{l}\text { Small businesses of all forms of property (in } \\
\text { the list approved by the territorial body of } \\
\text { Federal State Statistics Service). }\end{array}$ & $\begin{array}{l}\text { The structure of expenditure on technological innovation, } \\
\text { the amount of product innovation, the number of } \\
\text { employees. }\end{array}$ \\
\hline 4 2-science & $\begin{array}{l}\text { Information about performing } \\
\text { research and development }\end{array}$ & $\begin{array}{l}\text { Legal entities and their subdivisions, } \\
\text { performing research and development (except } \\
\text { small businesses) }\end{array}$ & $\begin{array}{l}\text { Personnel involved in } R \& D \text {, distribution of staff by fields } \\
\text { of science, the structure of the cost of } R \& D \text { and the } \\
\text { sources of their funding. }\end{array}$ \\
\hline
\end{tabular}

It should be noted that the first three forms represent only those subjects of innovation activity, which is included in the relevant list of the territorial body of Federal State Statistics Service. The author was not unable to read this list (perhaps because the primary data of the state statistical observations are confidential). Only the latter form "2-science" is required to be provided by all organizations performing $R \& D$.

August 27, 2013 Petrostat (territorial body of Federal State Statistics Service) published a statistical report "Research and development in 2012."with respect to business entities registered in the territory of St. Petersburg and Leningrad region. According to the report, in St. Petersburg and Leningrad region in 2012 R \& D was carried out by 429 organizations. Unfortunately, data on the distribution of these organizations by ownership are not available.

Such a small number of respondents, according to the author, can be caused primarily by the fact that not all organizations are accountable to the government statistics on their activities. The relatively small size of the penalty $(5$ 
000 rubles at the moment) for failure to provide information, as well as the rather vague requirement for organizations providing information ("organizations carrying out R \& D") contribute to the avoidance of subjects of innovation activity from additional reporting.

On the one hand, 429 organizations - is sufficient for sampling. On the other hand, there is the question of its representativeness. We can assume that those organizations that report in the prescribed manner are qualitatively different in structure of $R \& D$ costs and their effectiveness on those who are not accountable.

The analysis of the aforementioned statistical forms has been identified the following shortcomings:

Lack of comparability of periods of data collection. Form number 2 MP innovation (for small businesses) is provided every two years, the form number 4- innovation - once a year. According to the author, the dynamics of the innovation activities of small businesses is not less than of the other companies. It would be advisable to establish an annual delivery of form 2-MP innovation.

Inaccuracy of reflection of the existing situation in relation to the evaluation criteria which are determined by company's management, based only on internal beliefs, without reference to specific financial and economic indicators.

\subsection{Model of assessment of the impact of tax privilege}

Let us try nevertheless to form factor model assessing the impact of tax incentives under the law of St. Petersburg "On tax benefits" on the level of spending on research and development to obtain the missing ones through official statistical observation data, the Committee for Economic Development, Industrial Policy and Trade of Administration of St. Petersburg (for purposes of confidentiality (data provided by the author are not intended for public use), the author gives distorted absolute figures, but with preservation of the original proportions. According to the author this is no way can affect the results of the analysis, since this model assumes linear correlation between the factor and the resulting function (level of implementation of research and development)).

The sample included the period from 2008 to 2013 inclusive. Despite the fact that the benefit was actually introduced in 2009, the sample should include earlier periods and with the help of using regression analysis to see how the amount of benefit affected research and development.

These data are listed in Table 2 for each year.

It should be noted the need for a valuation of variables when moving from the absolute values of the data (factors and the resultant one) to the standardized deviations. For example:

$$
\begin{aligned}
R_{i t}^{*} & =\frac{\mathrm{R}_{\mathrm{it}}-\overline{\mathrm{R}}}{\sigma_{\mathrm{R}_{\mathrm{it}}}} \\
X_{i t}^{*} & =\frac{\mathrm{X}_{\mathrm{it}}-\overline{\mathrm{X}}}{\sigma_{\mathrm{X}_{\mathrm{it}}}}
\end{aligned}
$$

Where: $\sigma$ - mean square deviation;

$\bar{R}$ - arithmetical average $\mathrm{R}$.

Rationing variables solves the problem of comparability of different variables (e.g. interest rates on loans and level of spending on research and development). The data in Table 2 are normalized.

All calculations and graphics are made by using software package MathStat.

To construct a model we use the classical method of least squares (hereinafter - LSM).

\begin{tabular}{|c|c|c|c|c|c|c|c|}
\hline № Year & $\begin{array}{l}\text { y level of expenditures } \\
\text { for research and } \\
\text { development in the } \\
\text { whole of St. Petersburg } \\
\text { in the year }\end{array}$ & $\begin{array}{c}\mathrm{X}_{1} \text { subsidies, grants } \\
\text { received by } \\
\text { companies of St. } \\
\text { Petersburg on } \\
\text { research and } \\
\text { development }\end{array}$ & $\begin{array}{l}\mathrm{X}_{2} \text { level of expenditures } \\
\text { for research and } \\
\text { development in the whole } \\
\text { of St. Petersburg in the } \\
\text { previous year }\end{array}$ & $\begin{array}{l}\mathrm{X}_{3} \text { the average cost } \\
\text { of loans for small } \\
\text { and medium-sized } \\
\text { businesses in year } \mathrm{t} \text {, } \\
\text { offered by banks in } \\
\text { the region }\end{array}$ & $\begin{array}{l}\mathrm{X}_{4} \text { the volume of } \\
\text { direct budgetary } \\
\text { financing of public } \\
\text { research } \\
\text { organizations }\end{array}$ & $\begin{array}{c}\mathrm{X}_{5} \\
\text { Presence / } \\
\text { absence of } \\
\text { tax privilege }\end{array}$ & $\begin{array}{l}\mathrm{X}_{6} \text { the level of } \\
\text { gross domestic } \\
\text { product of St. } \\
\text { Petersburg }\end{array}$ \\
\hline 12005 & 2.22 & 2.14 & 2.21 & 7.87 & 8.12 & 0 & 120.97 \\
\hline 22006 & 2.12 & 2.43 & 2.22 & 6.54 & 8.56 & 0 & 123.76 \\
\hline 32007 & 2.35 & 2.96 & 2.12 & 6.43 & 7.54 & 0 & 140.81 \\
\hline 42008 & 2.29 & 4.8 & 2.35 & 6.12 & 8.23 & 0 & 149.33 \\
\hline 52009 & 2.75 & 5.88 & 2.29 & 6.34 & 9.1 & 0 & 154.44 \\
\hline 62010 & 3.13 & 6.75 & 2.75 & 6.06 & 9.24 & 0 & 179.80 \\
\hline 72011 & 3.56 & 7.27 & 3.13 & 5.67 & 9.53 & 0 & 201.09 \\
\hline 82012 & 3.93 & 7.59 & 3.56 & 4.41 & 9.84 & 1 & 220.11 \\
\hline 92013 & 4.44 & 8.01 & 3.93 & 4.29 & 10.04 & 1 & 270.18 \\
\hline
\end{tabular}

Table 2. Statistical data used to calculate (in arbitrary (given) monetary units) 
With Mathstat we make calculations of the first model with factors $\mathrm{X}_{1}, \mathrm{X}_{2}, \mathrm{X}_{3}, \mathrm{X}_{4}, \mathrm{X}_{5}, \mathrm{X}_{6}$. Data entered in the program are shown in Table 2 . We obtain the multiple regression equation and the observed value of t-criteria for each regression coefficient $a_{\mathrm{j}}$ :

$$
€\left(x_{1}, x_{2}, x_{3}, x_{4}, x_{5}, x_{6}\right)=0.281+0.575 * x_{1}+0.289 * x_{2}-0.126 * x_{3}+0.144 * x_{4}+0.035 * x_{5}-
$$

$0.008 * x_{6}$

To calculate the empirical value in t-criteria in situation of testing the hypothesis about the differences between two dependent samples (e.g. two samples of the same test with a time interval), the following formula is used:

$\mathrm{t}=\frac{\left|\mathrm{M}_{\mathrm{d}}\right|}{\sigma_{\mathrm{d}} / \sqrt{\mathrm{N}}}$

Where $M_{d}$ - the average difference of values, and $\sigma_{d}$ - standard deviation of the differences.

Number of degrees of freedom is calculated as

$\mathrm{df}=\mathrm{N}-1$

$\mathrm{t}_{\text {observ }}$ modulo: 0.584 .652 .761 .341 .413 .340 .63

Let us compare $\left|t_{\text {observ }}\right|$ with a table at a significance level $\delta=0.05 t_{\text {table }}=2.02$. observ t

As the $a_{0}$ is not statistically significant, then removing it from the equation, using the software package Mathstat we obtain the equation: $0.004 * x_{6}$

$€\left(x_{1}, x_{2}, x_{3}, x_{4}, x_{5}, x_{6}\right)=0+0.572 * x_{1}+0.308 * x_{2}-0.115 * x_{3}+0.174 * x_{4}+0.036 * x_{5}-$

$\mathrm{t}_{\text {observ }}$ modulo: 04.673 .131 .2623 .540 .4

From all statistically significant coefficients, coefficients $x_{1}, x_{2}, x_{5}$ may be recognized, because coefficients are more than 2.02 .

Coefficients at $x_{3}$ - can not be considered statistically significant, that's why we remove $x_{3}$ factor from the model.

Coefficients at $x_{4}$ - can not be considered statistically significant, that's why we remove $x_{4}$ factor from the model.

It should be noted that initially, when analyzing on a qualitative level it was impossible to conclude that these factors will be statistically insignificant. It is therefore their inclusion in the original calculation model is justified.

So, $x_{1}, x_{2}, x_{5}$ is left in the model.

With Mathstat we calculate the second model, with the factors $x_{1}, x_{2}, x_{5}$. We obtain multiple regression equation and observed value of the t-criteria for each regression coefficient $a_{\mathrm{j}}$ :

$€\left(x_{1}, x_{2}, x_{5}\right)=0.75 * x_{1}+0.228 * x_{2}+0.039 * x_{5}$

$\mathrm{t}_{\text {observ }}$ modulo: 10.393 .0143 .82

Let's compare $\left|t_{\text {observ }}\right|$ with a table value at significance level $\delta=0.05 c(n-m-1)=(47-3-1)=43$ degrees of freedom $t_{\text {table }}=2.02$ and calculate the significance coefficients in the Table 3.

Table 3. Calculation of significance coefficients

\begin{tabular}{ccccc}
\hline $\mathrm{y}$ & $\mathrm{X} 1$ & $\mathrm{X} 2$ & $\mathrm{X} 5$ \\
\hline $\mathrm{y}$ & & 1 & & \\
\hline $\mathrm{X} 1$ & 0.884148423 & & 1 & \\
\hline $\mathrm{X} 2$ & 0.526521959 & 0.533871035 & 1 & \\
\hline $\mathrm{X} 5$ & 0.441017751 & 0.273023712 & 0.045987724 & 1 \\
\hline
\end{tabular}

Let' consider two models: $x_{1}, x_{5} ; x_{2}, x_{5}$

Let's consider the model $x_{1}, x_{5}$ :

$\mathrm{t}_{\text {observ }}$ modulo: 44.552 .94

$€\left(x_{1}, x_{5}\right)=0.96 * x_{1}+0.032 * x_{5}$

Let's compare $\left|\mathrm{t}_{\text {observ }}\right|$ with a table value at significance level $\delta=0.05 \mathrm{c}(\mathrm{n}-\mathrm{m}-1)=(10-2-1)=43$ degrees of freedom $t_{\text {table }}=2.02$

As you can see, all of the coefficients are significant.

$A=\frac{100 \%}{n} * \sum\left|\frac{e_{i}}{y_{i}}\right|=\frac{100 \%}{47} * 4.869=10.36 \%$

$V=\frac{100 \%}{\bar{x}} \sqrt{\frac{\sum e_{i}^{2}}{n}}=\frac{100 \%}{5.32} \sqrt{\frac{20.85}{47}}=12.49 \%$

$\mathrm{F}_{\text {observ }}=1527.72>\mathrm{F}_{\text {table }}$

Let's consider the model $x_{1} x_{5}$ : 
$€\left(x_{1}, x_{5}\right)=0.98 * x_{1}+0.081 * x_{5}$

$\mathrm{t}_{\text {observ }}$ modulo: 24.564 .69

Let's compare $\left|t_{\text {observ }}\right|$ with a table value at significance level $\delta=0.05 c(n-m-1)=(10-2-1)=7$ degrees of freedom $t_{\text {table }}=2.02$

As you can see, all of the coefficients are significant.

$A=\frac{100 \%}{n} * \sum\left|\frac{e_{i}}{y_{i}}\right|=\frac{100 \%}{47} * 7.946=16.91 \%$

$V=\frac{100 \%}{\bar{x}} \sqrt{\frac{\sum e_{i}^{2}}{n}}=\frac{100 \%}{5,32} \sqrt{\frac{59.68}{47}}=23.87 \%$

$\mathrm{F}_{\text {observ }}=519.0835>\mathrm{F}_{\text {table }}$

All models are of good quality, all of them can be used for further research, but according to t-criteria factor $\mathrm{x}_{1}$ (44.55) is higher than factor $x_{2}$ (24.56), approximation errors in the first model is smaller than in the second one.

To further stages we examine the first model with $x_{1}, x_{5}$. We make assumptions:

- These factors are crucial and really show the true relationship

- multicollinearity in the model is small.

By t-criteria this model can be regarded as the most high-quality one.

To establish conclusively whether this is so, we will check multicollinearity in it.

We calculate the linear correlation coefficients between pairs of $Y$ and each factor, and mutually among all factors. An overall correlation matrix in Table 4 is made.

Table 4. Correlation matrix of factors

\begin{tabular}{cccc}
\hline & $Y$ & $X 1$ & $X 5$ \\
\hline$y$ & 1 & & \\
\hline$X 1$ & 0.884 & 1 & 1 \\
\hline$X 5$ & 0.441 & 0.273 & \\
\hline
\end{tabular}

We see, that correlation between $x_{1}$ and $x_{5}(0.273)$ is extremely weak, it can be said it is practically absent. We calculate the determinant of the matrix of inetr-factor correlation in Table 5.

\begin{tabular}{ccc}
\hline & $\mathrm{X} 1$ & $\mathrm{X} 5$ \\
\hline $\mathrm{X} 1$ & 1 & \\
\hline $\mathrm{X} 5$ & 0.273 & 1 \\
\hline
\end{tabular}

$\operatorname{det} r_{\mathrm{x}}=\operatorname{det}\left(\begin{array}{cc}1 & 0.273 \\ 0.273 & 1\end{array}\right) \approx 0.925$

det $r_{x} \approx 0.925 \rightarrow 1$, This means that the problem of multicollinearity is insignificant; we can say it is negligible. And given that the model coefficients were resistant to change of the model, we can decide that the problem of multicollinearity practically does not distort the results of the simulation, and its effects are negligible.

We can further analyze the model.

Thus, the model is obtained:

$€\left(x_{1}, x_{5}\right)=0.96 * x_{1}+0.032 * x_{5}$

The economic interpretation of multiple regression coefficients

$a_{1}=0.96$ - shows that an increase in the amount of subsidies, grants received by companies of St. Petersburg on research and development per 1 ruble, level of expenditure for research and development in the whole of St. Petersburg increases for 96 kopecks.

$a_{2}=0.032$ - shows that the introduction of tax incentives on average causes $3.32 \%$ of the total performed research and development.

Confidence intervals for the parameters of the multiple regressions

$\alpha_{j}: a_{j} \pm s_{a j} * t_{\text {table }, \delta,(n-m-1)}$

At the level of significance $\delta=5 \%$, using Mathstat calculations, we obtain $95 \%$ confidence intervals:

for $\alpha_{1}:(0.913 ; 1.004)$, for $\alpha_{2}:(0.005 ; 0.01)$

The width of the interval is small; it can be assumed that the accuracy of the model will be good.

Determination coefficient

$R^{2}=0.985$ 
Adjusted coefficient of determination $\tilde{R}^{2}=0.963$ shows that the change in the level of expenditure on R \& D - Y for $96.3 \%$ is caused by the cumulative change in such factors as the amount of subsidies, grants received by companies in St. Petersburg and the introduction of tax incentives.

The rest $3.7 \%$ is caused by changes in the value of other factors not included in the model, or undetected in this study and accidental ones.

As it is shown above, the introduction of a tax benefit on average causes $3.32 \%$ of the total volume of performed research and development. Given the level of spending on research and development, in Table 2, it can be calculated that the tax benefit for the period of 2011-2012 caused 0.096 conventional monetary units of additional costs for research and development.

In this case, from data obtained through the Committee for Economic Development, Industrial Policy and Trade of St. Petersburg Administration of the Federal Tax Service in St. Petersburg, the amount of claimed tax benefits for the same period was 0.156 monetary units.

Thus, we can conclude that the benefit is ineffective, since the direction of the shortfall of tax revenue funds directly to research and development would increase the amount of research and development carried out in the region.

Perhaps the constructed model is insufficiently reliable due to the lack of sufficient data array in the state statistical observations, as it was shown in the previous section. In other words, according to the author, the more representative set of statistics will be available to the researcher, the greater the number of factors could be included in the model, and the results will be of higher quality.

However, a number of limitations in the use of incentives do not promote its widespread deployment by subjects of innovative activity; perhaps this is why the privilege is ineffective.

The requirement for the implementation of investments in fixed assets of \$50 million rubles is relatively high, making it virtually impossible to use the benefits for certain products referred to in the Law. For example, investments in fixed assets for the organization of "Software Development, ready to use: development of system software, tools, applications" rarely reach 50 million rubles due to normal for such companies asset structure which does not involve significant investment in fixed assets.

It is proposed to consider the possibility of including another criteria for the possibility of applying the benefits for manufacturers of those products that do not require significant investments in fixed assets: to include in the concept of "investments" intangible assets, organized according to the Russian accounting standards; and / or lower the threshold of investments; and / or enter the criteria to be able to apply the privilege in the form of the relationship of payroll for the year to the average number of employees for taxpayers receiving revenue from the development of basic types of high-tech products that do not have material expression and thus often not demanding investments in fixed assets.

In order to include intangible assets in the concept of "investments" for the purposes of calculating the investment under the Article 11-5 of the Law, it is necessary to present the concept of investments:

A) separately for article 11-5;

B) as follows:

«For the purposes of this article, except for investments referred to in paragraph 1 of Article 11-4 also generated intangible assets in accordance with accounting are referred.

When calculating the amount of investments in the form of intangible assets referred to in paragraph 1 of this Article, intangible assets, formed in accordance with the accounting carried on the balance sheet of the taxpayer, are carried at cost, based on accounting data. The sum of investments in the form of intangible assets referred to in paragraph 1 of this Article shall be reduced by the net book value of intangible assets on the balance sheet of the taxpayer, and excluded (retired) for the above mentioned period. The object of fixed assets may be involved in this calculation only once».

In addition, the list of products whose production allows the use of privilege under Article 11-5 of the Law is limited. It is not possible to apply the privilege to many companies involved in the development of innovative economy:

Computer production;

Production of fiber optic cables;

Production of electron-optical converters, image intensifiers, photoelectric devices;

Production of microwave devices;

Production of semiconductor elements, devices;

Manufacture of transmitting equipment for radio, radio-broadcasting or television;

Production of medical diagnostic and therapeutic equipment, surgical equipment;

Production of devices based on liquid crystals;

Production of lasers; 
Software development, ready to use: development of system software, tools, applications.

It is proposed to expand the list. It can be supplemented by, for example, the following types of high-tech products (in accordance with the National Classification of Products codes NC 005-93):

634095 Optoelectronic semiconductor elements;

634011 Semiconductor diodes;

634900 Different electronic devices;

636000 Special products for the production of electronic equipment;

403300 Input and output devices;

403500 Systems of information teleprocessing.

This will allow high-tech industries to apply the privilege.

As a result of testing methods on the example of federal incentives for companies - software developers, neutral result has been identified. Namely, the tax benefit for the period of 2011-2013 year caused 0.223 conventional monetary units of additional spending on research and development, while the amount of the shortfall in tax revenues from the use of incentives for the same period was 0.219 currency units. According to the author, the difference is within the measurement error (within the correlation error) and may not be indicative of the desirability or otherwise of the use of incentives.

\section{Conclusion}

Summing up, it should be noted that the author has done serious work to develop a methodology for assessing the budgetary impact of the use of tax incentives, and following results were achieved. Based on the correlation - regression analysis of statistical data, estimation methodology of budget efficiency of the application of the tax benefits is developed. The technique is to identify the size of the additional $R \& D$ expenses caused by the introduction of varying benefits, as well as in comparison with the values of these costs with the size of the budget shortfall in income due to the introduction of incentives. The procedure was approved by the example of insurance contributions and income tax. An example of inappropriate use is a regional the privilege of St. Petersburg on income tax for companies - manufacturers of high-tech products. Also, neutral character of benefits of mandatory insurance premiums for companies that develop software is proved.

Based on the foregoing, it can be concluded that the work demonstrates unreasonableness and illogicality of a unique solution of the question of tax incentives. Each individual tax benefit is an independent mechanism, ineffectiveness of which can be corrected through the improvement of the benefit itself.

With the proposed method, it is possible to determine the appropriateness of this or that benefits from the point of view of how it is more profitable or loss-making than direct funding of $R \& D$.

\section{References}

Bezrukova T.L., Morkovina S.S., Bezrukov B.A., Popkova E.G. (2013). Methodological Approach to the Identification of Predictive Models of Socio-economic Processes for Investment and Innovative Development of Enterprises / World Applied Sciences Journal. Vol. 26, No.1. - Pp. 20-27. - Refer.: Pp. 26-27 (9 titl.).

Bezrukova, T. and Bezrukov B. (2013). "Methodological Approach to the Identification of Predictive Models of Socio-Economic Processes for Investment and Innovative Development of Enterprises“,World Applied Sciences Journal. Vol. 26, No.1. Pp. 20-27.

Bezrukova T. and Petrov P. (2012). Determination of relevance of use of the mechanism of strategic controlling in a control system of the industrial organization//Economy in the industry. No. 2. Pp. 61-72.

Bezrukova T. and Petrov P. (2013). Formation of the concept of strategic controlling at the industrial enterprises//Management accounting. No. 2. Pp. 31-40.

Bezrukova T.L. and Bezrukov B.A. (2013). Prognostic management of investment and innovation development of furniture manufacture. // "Production management. Account, analysis, finance". International scientific conference. London on October 19-26, 2013.

Mansfield E., Switzer L. (1998). How effective are Canada's direct tax incentives for R\&D? //Canadian Public Policy. 1985. No.11. Pp.241-246.; R\&D, Innovation and Competitiveness: an Evaluation of the R\&D Tax Concession. Australian Bureau of Industry Economics. Australian Governement Publishing Service. Canberra. 1993. P. 37; Bloom, N., Griffith, R., Van Reenen, J. Do R\&D tax credits work? Evidence from an international panel of countries 1979-1998. Institute for Fiscal Studies. 1998. Working Paper W99/8.

Mansfield E., Switzer L. (1985). How effective are Canada's direct tax incentives for R\&D? // Canadian Public Policy. 1985. No.11. Pp.241-246.

Review of Studies of the Effectiveness of the Research Tax Credit. (1996) / General Accounting Office. 1996. USA, Washington DC.

Swenson, C.W. (1993). Some tests of the incentives effects of the research and experimentation tax credit // Journal of Public 
Economics. 1992. No. 49. P. 203-218; McCutchen, W.M. Estimating the impact of the R\&D tax credit on strategic groups in pharmaceutical industry. // Research Policy. 1993. No.22. P.339.

Tax Incentives for Scientific Research and Experimental Development. Response to the Department of Finance, Canada. (2007). DOI: http://www.kpmg.ca/en/services/tax/documents/SRED_Response_FIN.pdf, KPMG LLP, Canada, 2007. 